\title{
Waveform Inversion Methods for the Earthquake Source
}

\author{
Shingo Yoshida \\ Earthquake Research Institute, The University of Tokyo, Bunkyo-ku, Tokyo 113, Japan

\begin{abstract}
Recent developments in waveform inversion for inferring earthquake source behaviour are reviewed from the viewpoint of methodology. Particular attention is paid to the source parametrization used in the inversion methods. We also discuss the dependence of the solution on the data, the Green's functions, and the stabilizing constraints.
\end{abstract}

\section{Introduction}

Recent developments in waveform inversion method for inferring earthquake source behaviour, together with the establishment of high-quality digital seismograph networks and advances in computer technology, have led to great progress in understanding earthquake source behaviour. Using waveform inversion methods, the detailed rupture process of the earthquake can be retrieved from observed data. Also moment tensors for many moderate and large earthquakes can be determined in a routine way. We will review recent studies of the earthquake source by waveform inversion from the viewpoint of the methodology employed, with particular attention paid to the source parametrization used in the inversion. Of course, trial and error modeling with careful treatment of the data can yield important knowledge about the source (e.g., Sato, 1985; Umeda, 1990), but this paper limits its discussion to the inversion analysis. As the purpose of this special issue is to discuss research primarily by Japanese seismologists, some important papers by workers outside Japan may have been omitted.

In Sec. 2, we will group the many inversion methods by source parametrization and discuss the advantages of each of them. In Secs. 3 and 4 the effects of the use of different data and accurate Green's functions will be presented. In Sec. 4, we will describe efficiency of the stabilizing constraints. Discussion of inverse theory in general is beyond the scope of this paper. This subject is summarized, for example, in books written by Aki and Richards (1980) and by Tarantola (1987), and in a review by Matsu'ura (1991).

\section{Source Parametrization}

To understand the kinematic behaviour of the earthquake source, one must determine the moment rate tensor $\dot{M}$ as a function of time and space. In general a moment rate tensor has six independent elements, i.e.,

Received April 6, 1992; Accepted August 9, 1993 


$$
m_{1}=\dot{M}_{x x}, \quad m_{2}=\dot{M}_{x y}, \quad m_{3}=\dot{M}_{x z}, \quad m_{4}=\dot{M}_{y y}, \quad m_{3}=\dot{M}_{y z}, \quad m_{6}=\dot{M}_{z z} .
$$

If we restrict the source to a purely deviatoric source by setting the trace of the moment tensor to zero, we have five independent elements. One way of choosing the five independent elements of the deviatoric source is

$$
\begin{aligned}
\dot{M}= & m_{1}\left(\begin{array}{ccc}
1 & 0 & 0 \\
0 & 0 & 0 \\
0 & 0 & -1
\end{array}\right)+m_{2}\left(\begin{array}{lll}
0 & 1 & 0 \\
1 & 0 & 0 \\
0 & 0 & 0
\end{array}\right)+m_{3}\left(\begin{array}{lll}
0 & 0 & 1 \\
0 & 0 & 0 \\
1 & 0 & 0
\end{array}\right) \\
& +m_{4}\left(\begin{array}{ccc}
0 & 0 & 0 \\
0 & 1 & 0 \\
0 & 0 & -1
\end{array}\right)+m_{5}\left(\begin{array}{lll}
0 & 0 & 0 \\
0 & 0 & 1 \\
0 & 1 & 0
\end{array}\right) .
\end{aligned}
$$

One merit of this choice is that the source is decomposed into double-couple components.

To represent the moment rate function $m_{i}(t, x)$ in terms of a finite number of parameters, we express the source as a sum of many point sources in space and expand the source time function of each along the time axis using some basis function $s(t)$, such as an isosceles triangular function (Fig. 1), a boxcar type function, or a spline function, as

$$
m_{i}(t, \boldsymbol{x})=\sum_{k=1}^{K} \sum_{j=1}^{J} a_{i j k} s\left(t-T_{j} ; p\right) \delta\left(\boldsymbol{x}-\boldsymbol{x}_{k}\right) \quad i=1, \cdots, I
$$

where $a_{i j k}$ is the expansion coefficient, $p$ is a parameter such as a rise time that specifies the shape of the basis time function $s(t)$, and $I$ is taken to be 6 for a general source including an isotropic component and 5 for a deviatoric source. Seismic waveforms $F(t)$ at the receiver $y$ are written as

$$
F(t, y)=\sum_{i=1}^{I} \int m_{i}(t, \boldsymbol{x}) * g_{i}(t, \boldsymbol{y} ; \boldsymbol{x}) \mathrm{d} \boldsymbol{x} .
$$

Here, according to the data used in analysis, waveforms may mean displacements, velocities, or seismograms including the instrumental response; $g_{i}(t, \boldsymbol{y} ; \boldsymbol{x})$ is the corresponding Green's function $\left(F(t)\right.$ excited by the source of $\left.m_{i}(t)=\delta(t)\right)$; and $*$ is a
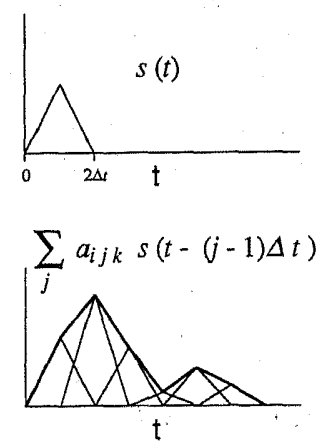

Fig. 1. Parametrized source time function in terms of overlapping isosceles triangles. 
convolution operator. Putting Eq. (1) into Eq. (2), we obtain

$$
F(t, y)=\sum_{i=1}^{I} \sum_{j=1}^{J} \sum_{k=1}^{K} a_{i j k} f_{i}\left(t-T_{j}, y ; x_{k}, p\right)
$$

with

$$
f_{i}\left(t, \boldsymbol{y} ; \boldsymbol{x}_{k}, p\right)=s(t ; p) * g_{i}\left(t, \boldsymbol{y} ; \boldsymbol{x}_{k}\right) .
$$

Note that the waveforms are linearly related to $a_{i j k}$, but nonlinearly related to $T_{j}, \boldsymbol{x}_{k}$ and $p$. Inversion methods for the earthquake source are basically designed to find model parameters that minimize the misfit between the synthetic waveform and the observed data. If we divide the time and space into a network of grids with a time-grid interval of $\Delta t$ and a space-grid interval of $\Delta x$, and then fix $T_{j}$ and $x_{k}$ at $(j-1) \Delta t$ and $(k-1) \Delta x$, respectively, the inversion becomes a linear procedure for determining the expansion coefficient $a_{i j k}$ in the model space as shown in Fig. 2. If we take any of $T_{j}, \boldsymbol{x}_{k}$, and $p$ as unknown parameters in addition to $a_{i j k}$, the problem is nonlinear.

When assuming a line source, the $k$-axis (space axis) in Fig. 2 is one-dimensional, but when we divide a fault lying on the $x y$-plane into $M \times N$ grids, $k$ is a pointer to a grid point in a two-dimensional plane which is given by $x_{k}=((m-1) \Delta x,(n-1) \Delta y)$ with $k=M(n-1)+m$. Although we used a delta function as a basis function to expand $m_{i}(t, \boldsymbol{x})$ along the space axis, other functions such as a boxcar function or a spline function are also sometimes used for the spatial expansion.

As an inversion based on Eq. (3) expanding over the whole model space requires too many free parameters, for a practical scheme the expansion has been limited to a portion of the model space by setting one or two of $I, J$, and $K$ to 1 . In other words, the parametric model expressed by Eqs. (1) and (3) includes most of the models so far used as special cases.

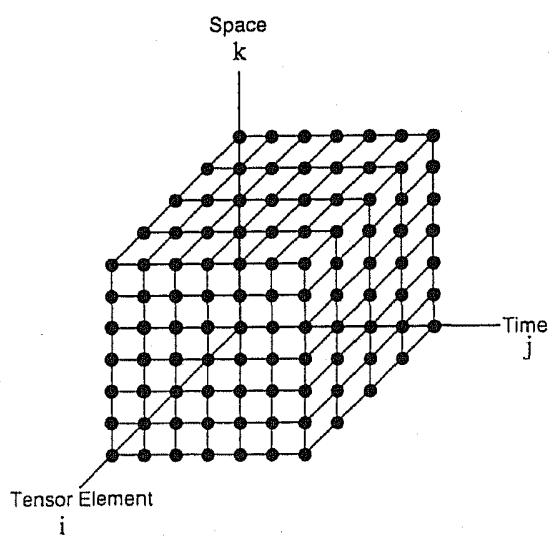

Fig. 2. Model space. The moment rate function may be expanded as $m_{i}(t, x)=$ $\sum_{k=1}^{K} \sum_{j=1}^{J} a_{i j k} s\left(t-T_{j} ; p\right) \delta\left(x-x_{k}\right) \quad i=1, \cdots, I$.

Vol. 43, No. 3, 1995 


\subsection{Moment tensor inversion}

In Subsecs. 2.1 to 2.3, we consider models in which two of $I, J$, and $K$ in Eqs. (1) and (3) are set to 1 , i.e., the source function is expanded along only one axis.

Recently many investigators have carried out moment tensor inversion using parametrizations such as

$$
m_{i}(t)=a_{i} s(t) \quad F(t)=\sum_{i} a_{i} f_{i}(t)
$$

This formulation assumes a single point source both spatially and temporally, which is obtained by putting $J=K=1$ into Eqs. (1) and (3) without expansion along the time and space axes (Fig. 3). Kanamori and Given (1981) determined the moment tensors of four shallow earthquakes using long-period surface waves in a linear programming approach. Nakanishi and Kanamori (1984) and Tanimoto and Kanamori (1986) modified their method to combine P-wave first motion data with surface wave data.

Dziewonski et al. (1981) and Dziewonski and Woodhouse (1983) developed centroid moment tensor (CMT) inversion to estimate not only the seismic moment tensor but also the coordinates (location and time) of the centroid of the source using long-period body and surface wave data. They synthesized waveforms by summation of normal modes. Because they also determined the centroid coordinates the problem is nonlinear. CMT inversion method has been used by many seismologists (e.g., Suetsugu and Nakanishi, 1988; Fukushima et al., 1989; Kawakatsu, 1990, 1991; Nakanishi et al., 1991; Yoshida and Abe, 1992). Some of these works fixed the centroid coordinates to make the problem linear. For example, Nakanishi et al. (1991) attempted to determine the long-period moment tensors of near earthquakes by a sparse local network consisting of three stations after fixing the event location and origin time to the value reported in the Preliminary Determination of Epicenters (PDE) Weekly Listing.

It is difficult to treat short-period body waves by normal mode theory because we must sum a tremendous number of modes. A ray theoretical approach is useful for

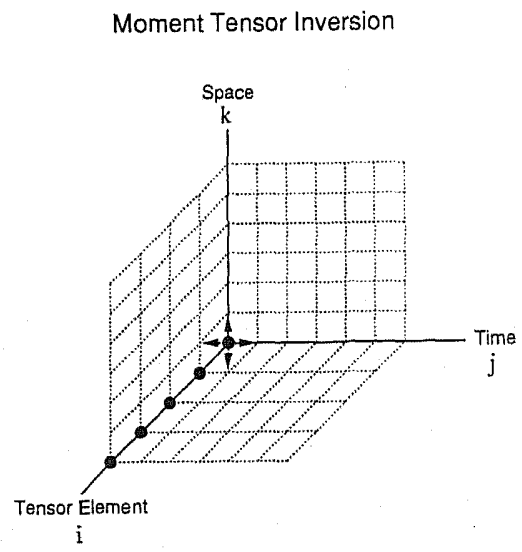

Fig. 3. The parametric source model expanded along the $i$-axis only, which is used in the moment tensor inversion. A single source in time and space is assumed. 
short-period body waves. Also, this approach can easily include local structural variation of the source and/or receiver regions. However a disadvantage is that the partial derivatives of waveforms with respect to the source coordinates are difficult to find so we must carry out inversions for trial and error depths. Honda and Seno (1989) presented a linear moment tensor inversion method that incorporated both body and surface wave data. They computed body waveforms based on ray theory and determined the source depth by finding the trial depth that minimized the misfit of the synthetic seismograms to the observed data.

\subsection{Time function inversion}

If we fix the earthquake mechanism to, for example, the mechanism obtained from $\mathrm{P}$-wave first motion data and assume a point source in space, the parametrization may be written as

$$
m(t)=\sum_{j} a_{j} s\left(t-T_{j}\right) \quad F(t)=\sum_{j} a_{j} f\left(t-T_{j}\right) .
$$

This formulation ignores the effects of finiteness of the source dimension. The expansion coefficients $a_{j}$ are determined so that the time function would yield a good fit to the data at many stations simultaneously.

The term "source time function" is often used to denote the following different definition:

$$
u(t, \phi)=\int m\left(t+\frac{x \cos \phi}{c}, x\right) \mathrm{d} x=\sum_{j} a_{j}^{*} s\left(t-T_{j}\right),
$$

where a line source along the $x$-axis is assumed for simplicity, $c$ is the phase velocity of the wave considered, and $\phi$ is the angle between the $x$-axis and the ray direction at the source. This should rather be called the "far-field source time function" while the time function $m(t)$ in Eq. (6) specifies the motion in the source region. The far-field source time function $u(t)$ may be regarded as the projection of $m(t)$ onto the $t$-axis in the model space using oblique rays with an angle of $\cos \phi / c$. Note that $u(t)$ depends on the station azimuth, hence the expansion coefficient $a^{*}{ }_{j}$ does so while $a_{j}$ in Eq. (6) is independent of it. As the Green's function in the far-field can be approximated by $g(t ; x)=g(t+x \cos \phi / c ; 0)$ (Aki and Richards, 1980), the waveform for the above expansion can be expressed as

$$
\begin{aligned}
F(t) & =\int m(t, x) * g(t+x \cos \phi / c ; 0) \mathrm{d} x=\int m(t+x \cos \phi / c, x) * g(t ; 0) \mathrm{d} x \\
& =\sum_{j} a^{*}{ }_{j} f\left(t-T_{j}\right)
\end{aligned}
$$

with

$$
f(t)=s(t) * g(t ; 0)
$$

This relation between the waveform and the expansion coefficient has the same form as Eq. (6), however, the expansion coefficients $a^{*}{ }_{j}$ are obtained for the individual stations

Vol. 43, No. 3, 1995 
(e.g., Kanamori and Stewart, 1978). Using the least squares solutions for several stations, we can estimate the fault length and rupture velocity from the directivity of the pulse width of the far-field source time function $u(t)$.

\subsection{Geodetic data inversion}

When we want to deduce the slip distribution on a fault plane with a fixed mechanism from static displacement data, we can use the following parametric model:

$$
M(\infty, \boldsymbol{x})=\sum_{k} a_{k} \delta\left(\boldsymbol{x}-\boldsymbol{x}_{k}\right) \quad F(\infty, \boldsymbol{y})=\sum_{k} a_{k} G\left(\infty ; \mathbf{x}_{k}\right),
$$

which corresponds to the case of $I=J=1$ in Eqs. (1) and (3). Miyashita and Matsu'ura (1978) and Ward and Barrientos (1986) reconstructed the spatial variation in slip magnitude of large shallow earthquakes by the geodetic data inversion. Yabuki and Matsu'ura (1992) inverted the geodetic data associated with the 1946 Nankaido earthquake taking the dip-slip and strike-slip components on subfaults as unknown parameters. Figure 4 shows their solution, which yields a good fit to the data for both horizontal displacements at triangulation points and vertical displacements along levelling routes.

Although geodetic data inversion may not, strictly speaking, belong to the category of waveform inversion, we treat it here because geodetic data can be expressed in the form of Eq. (3).

\subsection{Time dependent moment tensor inversion}

The source parametrization used in time dependent moment tensor inversion

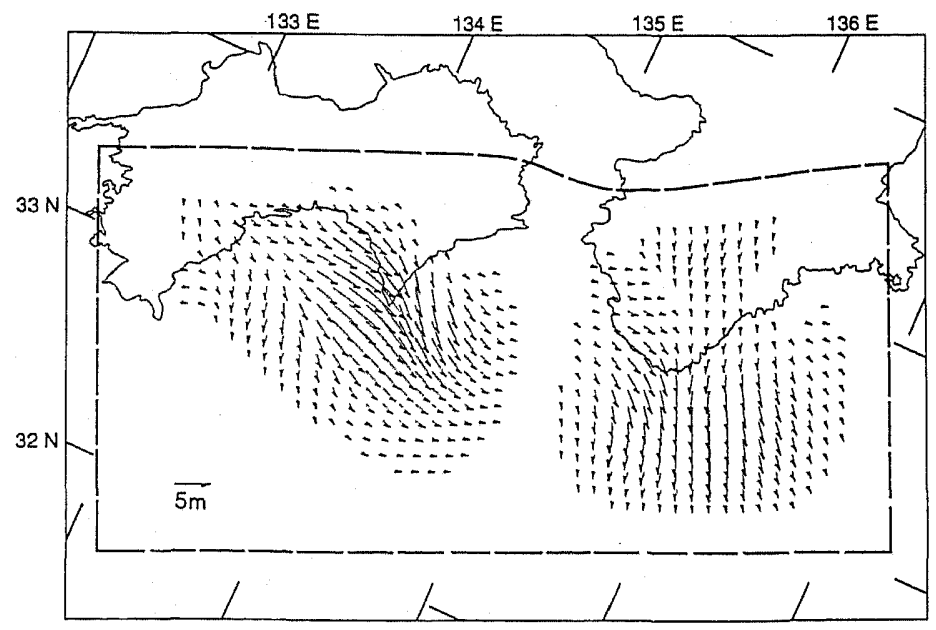

Fig. 4. The distribution of slip vectors inverted from the observed surface displacement data associated with the 1946 Nankaido earthquake. The area enclosed by the broken line indicates the surface projection of the model fault region taken on the curved plate boundary (after Yabuki and Matsu'ura, 1992). 
assuming a point source $(K=1)$ is schematically shown in Fig. 5, where the moment rate function is expanded on the $i j$-plane of the model space. The expression is written as

$$
m_{i}(t)=\sum_{j} a_{i j} s(t-(j-1) \Delta t) \quad F(t)=\sum_{i} \sum_{j} a_{i j} f_{i}(t-(j-1) \Delta t) .
$$

Time dependent moment tensor inversion is a method to determine independent time functions for the individual tensor elements, or equivalently, to obtain a moment tensor sequence at intervals of $\Delta t$.

Using this method in the frequency domain Dziewonski and Gilbert (1974) determined all six elements of the moment tensor, including the isotropic component, for two large deep earthquakes. They found that about $80 \mathrm{~s}$ before the abrupt onset of each event, the hypocentral region began to experience compression. This work was the first application of the moment tensor inversion to observed data. Mendiguren and Aki (1978) pointed out that long-period surface waveforms excited by the isotropic source of a deep earthquake are very similar to those excited by another independent component of a moment tensor, the vertical compensated linear vector dipole (CLVD) component, and thus the presence of a vertical CLVD component can bias the estimate of the isotropic component. Kawakatsu (1991) showed that using long-period body waves can resolve the isotropic component well. He analyzed 19 large deep earthquakes, and showed that no significant isotropic component existed.

Sipkin (1986) inverted body waveforms from four shallow-focus earthquakes $(M \sim 6)$, all of which had large non-double couple (NDC) components in the moment tensor solutions when the solution was constrained to be a point source in space and time. His inversion results suggested that the presence of an NDC component in the point source analysis could be physically explained by source multiplicities for one earthquake, rupture on nonplanar fault surface (time-varying mechanism) for another, and tensile failure under high-fluid pressure for the other two earthquakes. Dziewonski's group and Sipkin have been determining moment tensor solutions in a routine way and

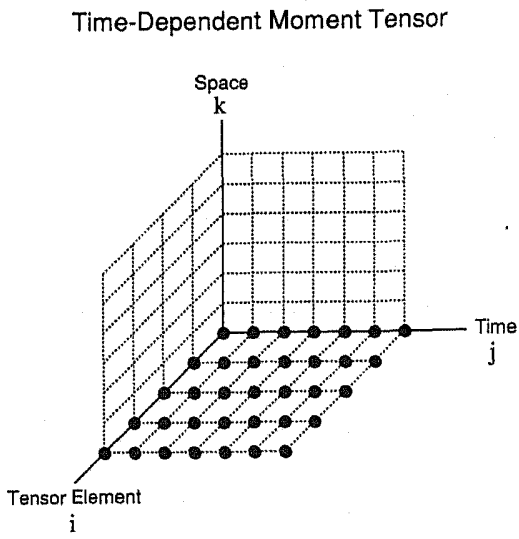

Fig. 5. The parametric model used in the time dependent moment tensor inversion. Spatially a point source is assumed.

Vol. 43, No. 3, 1995 
reporting them in PDE, when they assumed a temporally single source without expansion along the time axis.

Noise contained in the data often cause one or some tensors in the moment tensor sequence to have a large NDC component (Koyama, 1987). The size of the NDC component relative to the double couple (DC) component can be considered to be a measure of the quality of the solution. Time dependent moment tensor inversion always provides a solution with a time-varying focal mechanism; it is important to test whether the variation with time is statistically significant or not. Ruff and Tichelaar (1990) investigated the 1989 Loma Prieta earthquake by time dependent moment tensor inversion, but they concluded that the mechanism change with time was not statistically significant and proposed a fixed mechanism model as their final solution.

If our purpose is to find the source mechanism and source time function that yield the best fit to the data, a model used by Langston (1981) may be appropriate. He assumed that the time function was common to each moment tensor element and expressed the source as

$$
m_{i}(t)=b_{i} \sum_{j} c_{j} s(t-(j-1) \Delta t) \quad F(t)=\sum_{i} \sum_{j} b_{i} c_{j} f_{i}(t-(j-1) \Delta t)
$$

The coefficient $c_{j}$, which specifies the shape of the time function, is independent of the tensor elements $i$. As a result, the number of unknown parameters is reduced from $I \times J$ to $I+J$ so that the problem becomes more stable than time dependent moment tensor inversion in Eq. (8). As the formulation of the waveform contains the products of coefficients, $b_{i} c_{j}$, the inversion problem is nonlinear. The partial derivatives of synthetic waveforms with respect to the parameters depend on the chosen starting model, but the nonlinearity is not so strong.

\subsection{Inversion for spatial and temporal slip distribution}

In the above subsection we considered a point source in space. In this subsection

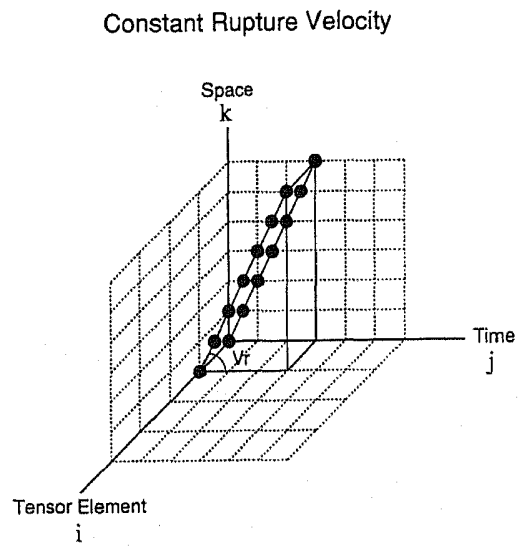

Fig. 6. The parametric model assuming that the rupture propagates at a constant velocity $V_{r}$. The dip-slip and strike-slip components on subfaults are taken as unknown parameters. 
we deal with inversion methods for obtaining the spatial distribution of moment release. If we assume a constant rupture velocity, we can treat this problem easily. Trifunac (1974) determined the spatial variation in slip on a given fault plane for both strike-slip and dip-slip components of the 1971 San Fernando earthquake. He divided a fault plane into several subfaults, denoting their location as $\boldsymbol{x}_{k}$, and set the rupture time $T_{k}$ of the $k$ th subfault to be $\left|x_{k}\right| / V_{r}$ assuming the rupture started at $\boldsymbol{x}=\mathbf{0}$ and propagated at a constant velocity $V_{r}$. The model (Fig. 6) is presented as

$$
\begin{aligned}
& m_{i}(t, x)=\sum_{k=1}^{K} a_{i k} s\left(t-\left|x_{k}\right| / V_{r}\right) \delta\left(x-x_{k}\right) \quad i=1,2 \\
& F(t)=\sum_{i=1}^{2} \sum_{k=1}^{K} a_{i k} f_{i}\left(t-\left|x_{k}\right| / V_{r} ; x_{k}\right),
\end{aligned}
$$

where $m_{1}=\dot{M}_{x z}$ and $m_{2}=\dot{M}_{y z}$ taking the $x y$-plane as the fault plane. This parametrization has the merit of linear inversion though the solution depends on an assumed value of $V_{r}$ and local variation in rupture velocity is not allowed. A similar parametrization was used by Mori and Shimazaki (1985) and Takenaka (1987).

Instead of assuming a constant rupture velocity, the rupture times $T_{k}$ 's are often taken as unknown parameters. The model may be expressed as

$$
m(t, x)=\sum_{k=1}^{K} a_{i k} s\left(t-T_{k}\right) \delta\left(\boldsymbol{x}-\boldsymbol{x}_{k}\right) \quad F(t)=\sum_{k=1}^{K} a_{k} f\left(t-T_{k} ; \boldsymbol{x}_{k}\right)
$$

as illustrated in Fig. 7. Here a subfault is allowed to slip only once. Although the problem is nonlinear, this model is considered to be physically reasonable because the rupture velocity must vary during an earthquake if the medium has inhomogeneous strength and/or accumulated stress, and because the wave energy would be radiated from a relatively narrow region near the rupture front. These features of the rupture behaviour are suggested by many results of rock fracture experiments and numerical simulation of the rupture process. This source parametrization has been adopted by

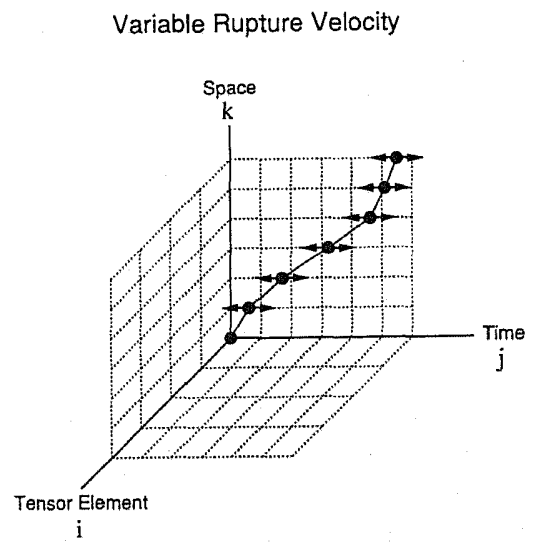

Fig. 7. The parametric model where the rupture time $T_{k}$ at the $k$ th subfault is taken as unknown. 
many authors, including Fukuyama and Irikura (1986, 1989), Takeo and Mikami (1987), Takeo (1988, 1989), Yoshida (1988, 1989), Beroza and Spudich (1988), Hatanaka and Takeo (1989), Yoshida and Koketsu (1990), and Fukuyama (1991). Figure 8 shows the slip distribution and the rupture front motion of the 1980 Izu-Hanto-Toho-Oki earthquake deduced from strong motion seismograms by Takeo (1988). He found that the rupture propagated irregularly and that the high slip region had fewer aftershocks.

Kikuchi and his colleagues (Kikuchi and Kanamori, 1982; Kikuchi and Sudo, 1984; Kikuchi and Fukao, 1985, 1987; Fukao and Kikuchi, 1987; Sugi et al., 1989) have determined the rupture processes of many large earthquakes. In their method, the source is presented as a sequence of subevents, and the subevent hypocenter $\boldsymbol{x}_{\boldsymbol{k}}$ is taken as an unknown as well as the scalar moment and the rupture time. Their source model is schematically shown in Fig. 9. The expression for their model has the same form as Eq. (11) but different unknown parameters. The source parameters of the subevents are iteratively determined in order of decreasing scalar moment by a stripping procedure. To find the parameters of the $k$ th subevent, they use data from which the contributions from the already determined subevents have been subtracted.

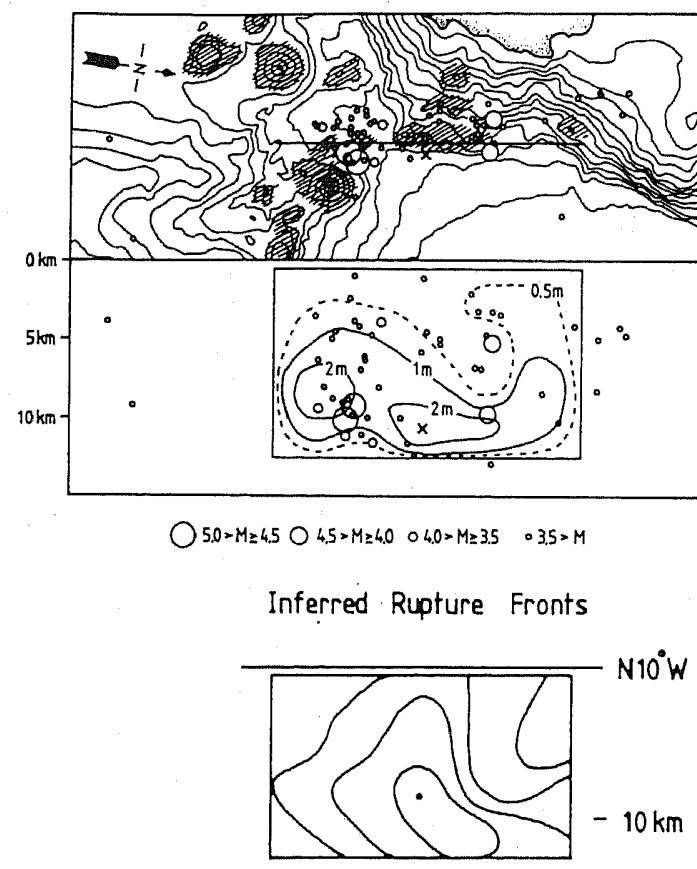

(a)

(b)

(c)

Fig. 8. The rupture process of the 1980 Izu-Hanto-Toho-Oki earthquake deduced from strong motion seismograms (after Takeo, 1988). (a) Distribution of the epicenters of the aftershocks. The small monogenetic submarine volcanoes are represented by shaded areas in the submarine topography. (b) Comparison with the slip distribution and the aftershock distribution. (c) The rupture fronts at every $2 \mathrm{~s}$. 


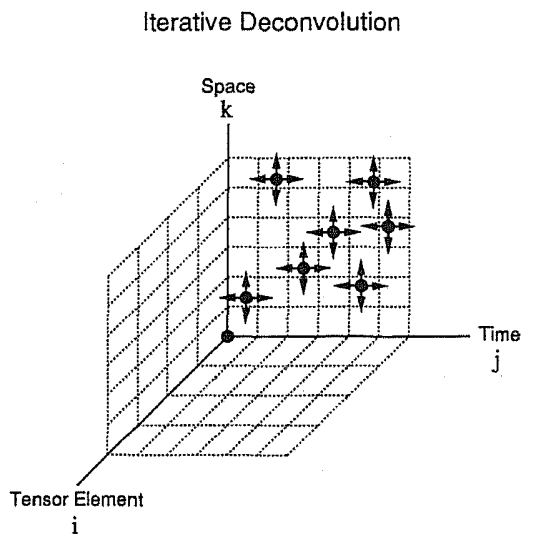

Fig. 9. The parametric model where the rupture time $T_{k}$ and location $x_{k}$ of the $k$ th subevent are taken as unknown.

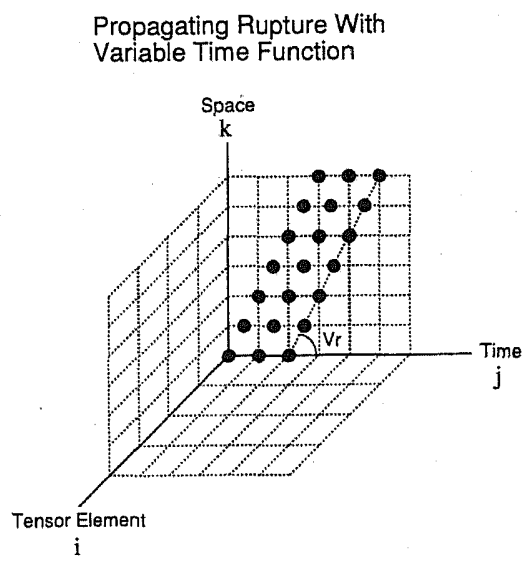

Fig. 10. The parametric model allowing each subfault to slip more than once as the rupture front passes at a velocity of $V_{r}$.

In inversions where the subfault is allowed to slip only once $(J=1)$, the resulting image strongly depends on the parameters, $p$, such as the duration time and rise time, that specify the shape of the source time function $s(t ; p)$. In many cases (e.g., Kikuchi and Kanamori, 1982; Mori and Shimazaki, 1985), the inversion procedure is run for various duration times to find what value gives the least error. Alternatively Yoshida (1988), Fukuyama and Irikura (1989) and Fukuyama (1991) treated the rise time as one of the unknown parameters to be determined by the inversion.

Olson and Apsel (1982) presented a model in which subfaults were allowed to slip more than once as the rupture front passed (Fig. 10). The problem was linear because the rupture time was specified a priori corresponding to an assumed average rupture velocity $V_{r}$ :

Vol. 43, No. 3, 1995 


$$
\begin{aligned}
& m(t, x)=\sum_{k=1}^{K} \sum_{j=1}^{J} a_{j k} s\left(t-\left|x_{k}\right| / V_{r}-(j-1) \Delta t\right) \delta\left(x-x_{k}\right) \\
& F(t)=\sum_{k=1}^{K} \sum_{j=1}^{J} a_{j k} f\left(t-\left|x_{k}\right| / V_{r}-(j-1) \Delta t ; x_{k}\right) .
\end{aligned}
$$

By allowing each point on the fault to slip several times $(=J)$ the local rupture velocity was allowed to differ from the average rupture velocity. This model can be also regarded as a model with different time functions depending on subfaults. Similar parametrizations were used by Hartzell and Heaton (1983) and Yoshida (1992), where $J$ was set at from 3 to 5 .

lida and Hakuno (1984) did not use any assumption on rupture propagation. Their model, shown in Fig. 11, is considered the most flexible among the parametric models expanded on the $j k$-plane. The source and the synthetic waveform are written as

$$
\begin{aligned}
& m(t, x)=\sum_{k=1}^{K} \sum_{j=1}^{J} a_{j k} s(t-(j-1) \Delta t) \delta\left(\boldsymbol{x}-\boldsymbol{x}_{k}\right) \\
& F(t)=\sum_{k=1}^{K} \sum_{j=1}^{J} a_{j k} f\left(t-(j-1) \Delta t ; \boldsymbol{x}_{k}\right),
\end{aligned}
$$

where $J$ and the duration time $(J-1) \Delta t$ are large enough to allow all the points of the fault to slip at any time. The problem is linear but the freedom of the solution increases tremendously, which may cause instability in the solution. Yoshida (1992) applied this same parametric model to the 1987 Andreanof Islands earthquake, but introduced a smoothing constraint to stabilize the problem. Figure 12 shows his result denoting the slip during every $10 \mathrm{~s}$. In spite of the fact that the rupture velocity was not assumed $a$ priori, the propagating rupture was successfully recovered. This may be because the data were available at a large number of well distributed stations. Das and Kostrov (1990) and Takeo (1992) have adopted similar parametrizations.

Seno and Honda (1990) computed waveforms using the formulation

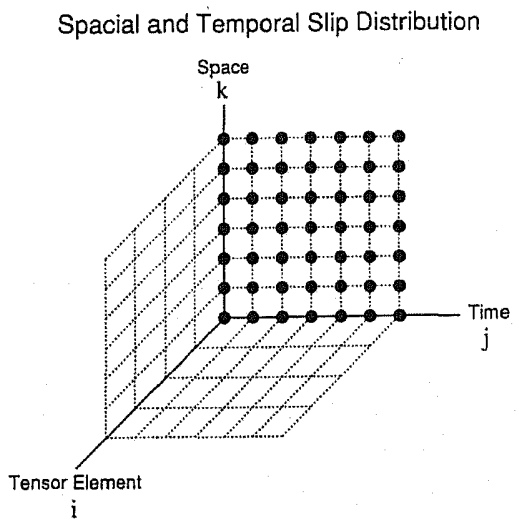

Fig. 11. The parametric model allowing all the points to slip at any time without prescribed rupture velocity. 


$$
\begin{aligned}
& m(t, x)=\sum_{k=1}^{K} \sum_{j=1}^{J} a_{j} s\left(t-\left|x_{k}\right| / V_{r}-(j-1) \Delta t\right) \delta\left(x-x_{k}\right) \\
& F(t)=\sum_{k=1}^{K} \sum_{j=1}^{J} a_{j} f\left(t-\left|x_{k}\right| / V_{r}-(j-1) \Delta t ; x_{k}\right),
\end{aligned}
$$

which assumes homogeneous slip distribution over the fault (the subscript of the coefficient $a_{j}$ does not contain $k$ specifying the hypocenter). Their main purpose was to retrieve the rupture depth extent by waveform inversion.

\subsection{Inversion for space and time dependent moment tensor}

In Subsec. 2.5, the mechanism was fixed $(I=1)$ or the fault plane was fixed with two unknown elements of the slip vector $(I=2)$. In recent work, earthquake sources have been studied with many point sources distributed in space and time, with the moment tensor of each point source being determined. If we remove, from the time dependent moment tensor inversion in Eq. (8), the constraint that the hypocentral coordinate is fixed during the earthquake, or if we remove the constraint that the mechanism is fixed from the model by Kikuchi and Kanamori (1982), we obtain the
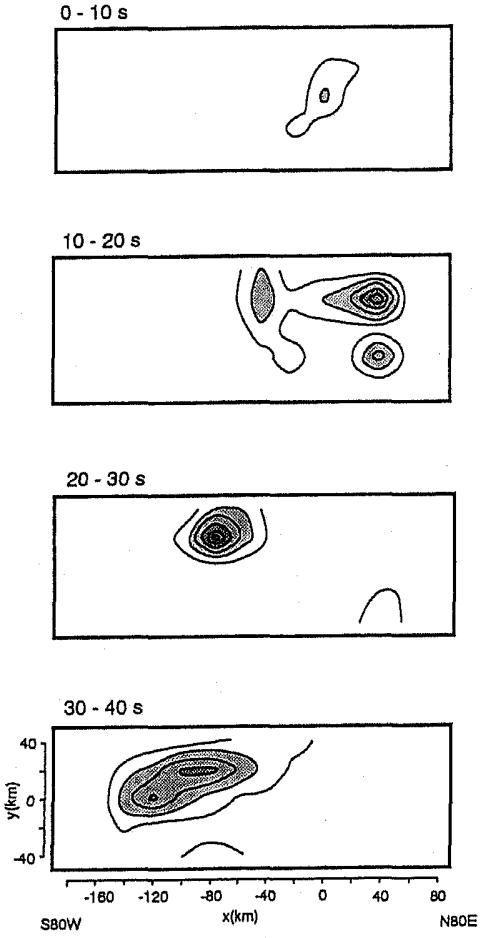
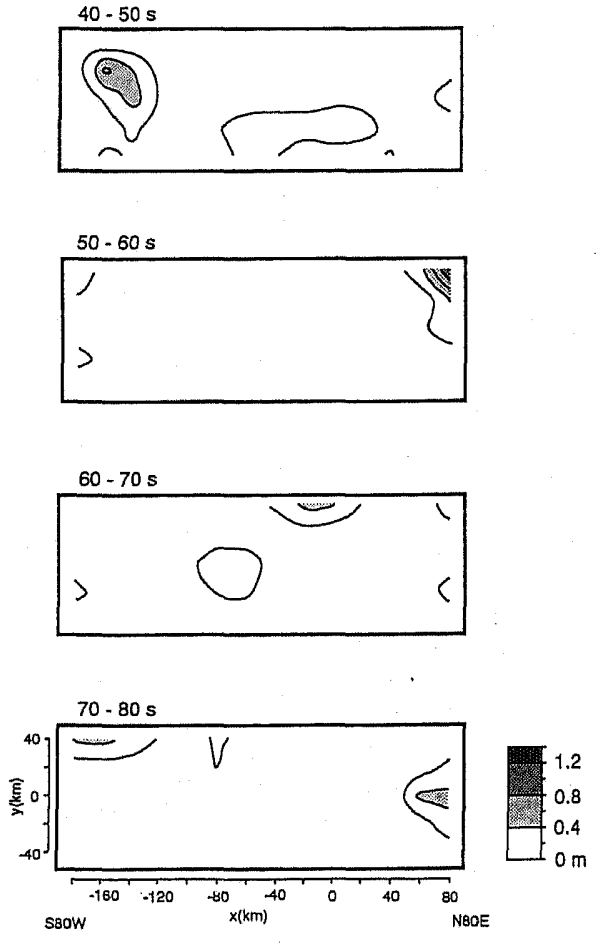

Fig. 12. Estimated slip during every $10 \mathrm{~s}$ for the 1986 Andreanof Islands earthquake. Though slip is allowed to occur at any time, propagating rupture is recovered (after Yoshida, 1992).

Vol. 43, No. 3, 1995 


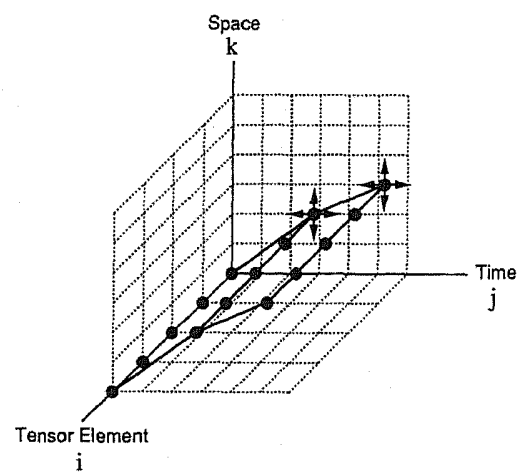

Fig. 13. The parametric model used in the space and time dependent moment tensor inversion. If we remove the point source constraint from the model in Fig. 5, or if we remove the fixed mechanism constraint from the model in Fig. 9, we obtain this model.

following parametrization (Fig. 13):

$$
m_{i}(t, \boldsymbol{x})=\sum_{k} a_{i k} s\left(t-T_{k}\right) \delta\left(\boldsymbol{x}-\boldsymbol{x}_{k}\right) \quad F(t)=\sum_{i} \sum_{k} a_{i k} f_{i}\left(t-T_{k} ; \boldsymbol{x}_{k}\right) .
$$

Initial attempts to determine the space and time dependent moment tensor by Burdick and Mellman (1976) and Strelitz (1980) consisted in part of a trial and error procedure. The hypocentral coordinates, $\boldsymbol{x}_{k}$ and $T_{k}$, of the subevents were not automatically determined. They first identified the phase radiated from the same subevent in the records at several stations, and then carried out hypocenter determination using the arrival time of the identified phase. Next they performed moment tensor inversion. This procedure was repeated in the order of decreasing moment tensor.

Hirata and Kawasaki (1988), Kikuchi and Kanamori (1991), and Yoshida and Abe (1992) have carried out such inversions in a more automated way. As this paramteric model is rather complex, the solution tends to be unstable and to have a large NDC component. Kikuchi and Kanamori (1991) extended their earlier method so that the subevent mechanisms were allowed to vary during the earthquake. To stabilize the problem, they restricted each subevent to be a double-couple source by constraining the determinant of the moment tensor to be zero, and further constrained the tensile axis of the moment tensors to be within a certain range around that of the first-motion mechanism. Figure 14 shows their results indicating the time sequence, location and mechanism of subevents for the 1976 Guatemala earthquake.

The above model denoted by Eq. (15) allowed each subfault to slip once with a common time function. Removing this constraint yields

$$
\begin{aligned}
& m_{i}(t, x)=\sum_{k=1}^{K} b_{i k} \sum_{j=1}^{J} c_{j k} s\left(t-T_{k}-(j-1) \Delta t\right) \delta\left(x-x_{k}\right) \\
& F(t)=\sum_{i=1}^{I} \sum_{j=1}^{J} \sum_{k=1}^{K} b_{i k} c_{j k} f_{i}\left(t-T_{k}-(j-1) \Delta t ; x_{k}\right) .
\end{aligned}
$$




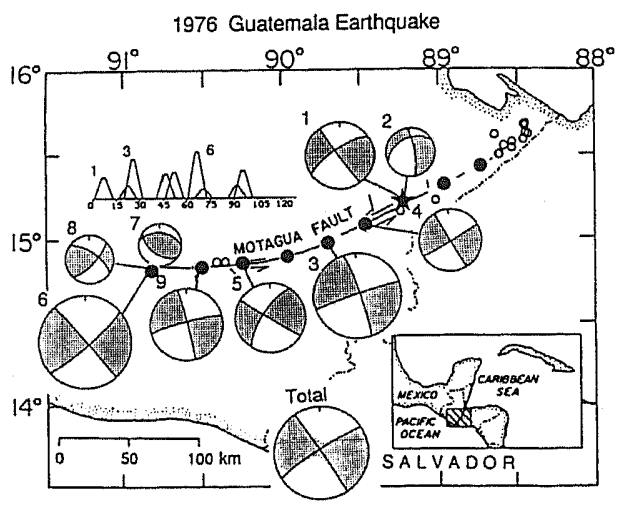

Fig. 14. Time sequence and location of subevents of the 1976 Guatemala earthquake. The area of the mechanism diagrams is proportional to the seismic moment (after Kikuchi and Kanamori, 1991).

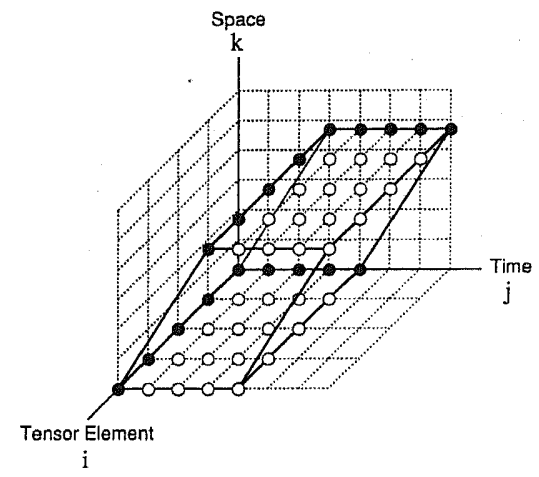

Fig. 15. The parametric model composed of two subevents of different mechanisms and different source time functions. The expansion coefficients assigned to open circles are not independent parameters (see the text).

This model (Fig. 15) can be considered as a sequence of Langston's (1981) sources. This model was used by Ekstrom (1989) and Kuge and Kawakatsu (1990). Kuge and Kawakastu (1990) analyzed the source mechanism of a deep earthquake using this parametrization setting $K=2$. Before the inversion they identified the second subevent in each seismograms by trial and error and determined the relative time $\left(T_{2}\right)$ and location $\left(x_{2}\right)$ of the second subevent by the directivity analysis. Next they performed a waveform inversion of the source mechanisms and the source time functions of the two subevents fixing the locations of the subevents.

Extending Langston's (1981) source Eq. (9) to a moving source, we get

$$
m_{i}(t, \boldsymbol{x})=b_{i} \sum_{k} c_{k} s\left(t-\left|\boldsymbol{x}_{k}\right| / V_{r}\right) \delta\left(\boldsymbol{x}-\boldsymbol{x}_{k}\right) \quad F(t)=\sum_{i} \sum_{k} b_{i} c_{k} f_{i}\left(t-\left|\boldsymbol{x}_{k}\right| / V_{r} ; \boldsymbol{x}_{k}\right) .
$$

Vol. 43, No. 3, 1995 


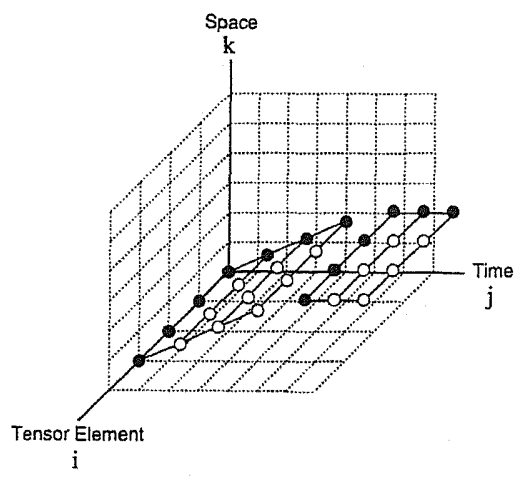

Fig. 16. The parametric model composed of a propagating source and a point source with different mechanism to each other.

Ekstrom (1989) used four types of source models to examine the 1985 Michoacan earthquake, one of which was this model. Nabelek (1985) recovered the source process of the $1980 \mathrm{El}$ Asnam, Algeria, earthquake. He applied this model to the first shock and the source denoted by Eq. (9) to the second shock. The combined model he used in the inversion is shown in Fig. 16.

\subsection{Model dependence of the solution}

So far we have seen many types of source models. Of course the source image inferred from the data depends on which parametrization we use. In order to obtain reliable solutions for the detailed source process, we must examine the dependence on the parametric model. Ekstrom (1989) started from a simple model, and gradually applied more complex models to analyze the 1985 Michoacan earthquake. When the improvement in fit was very small with an increasing number of free parameters, a simpler model was selected as a preferable solution. His results showed that the spatial distribution of moment was well explained both by a model of unilateral rupture with a propagation velocity of $2.4 \mathrm{~km} / \mathrm{s}$ and by two point sources with the same mechanism separated by $95 \mathrm{~km}$ (Fig. 17). A more complex model did not reduce the misfit by a large amount. Such an approach from simple model analysis to complex model analysis has been often taken. Another possible approach is to start with a very complex model with many free parameters. For example we can first use the parametrization of Eq. (3) to determine the coefficients $a_{i j k}$ in the entire model space. Even if we use adequate constraints in addition to the data, only a very vague image of the source would be obtained. However we could roughly determine the regions with strong moment release in the model space. Then we could use a more restricted model, for example, constraining the moment of the grid region which had small moment in the first solution to be zero. We can gradually make the constraint stronger until the agreement between the synthetics and the data becomes poor. This approach might enable us to avoid getting a local minimum point and to obtain a solution more quickly. If we start from a simple model, we must run many inversions for many sets of fixed parameters because the simpler model has the larger number of fixed parameters. This is rather similar to trial and 


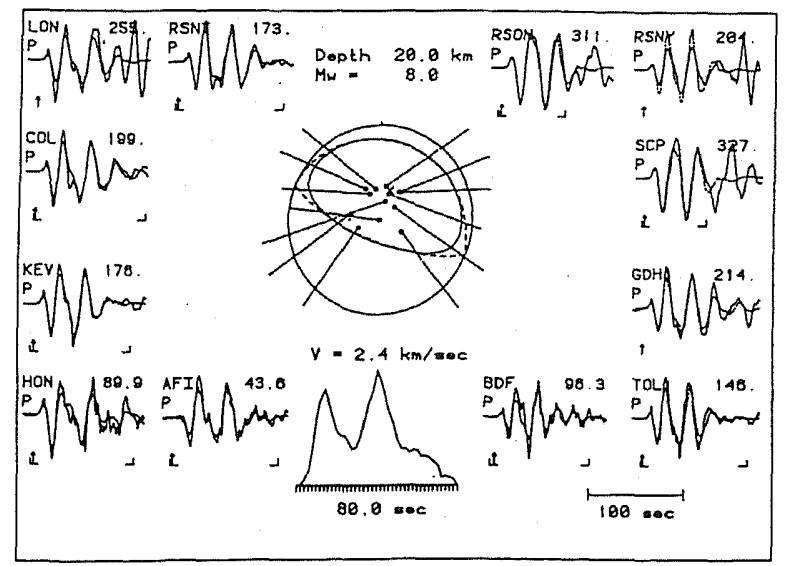

(a)

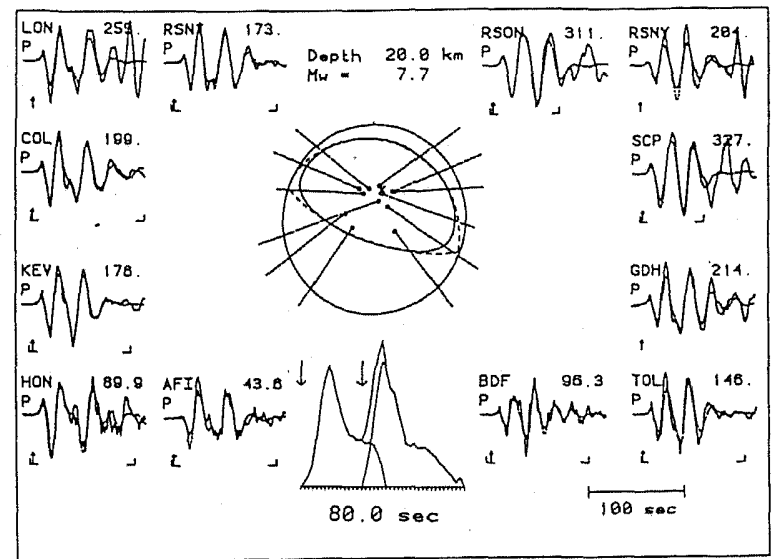

(b)

Fig. 17. Inversion results for the 1985 Michoacan earthquake using different source parameterizations. Observed and synthetic seismograms are also shown (after Ekstrom, 1989). (a) The rupture was assumed to propagate at $2.4 \mathrm{~km} / \mathrm{s}$. The mechanism and the slip distribution along the fault length were determined from the data. (b) The mechanism common to the two point sources and the time function of each were recovered. The two source time functions and their sum are indicated.

error modeling. If we fail to thoroughly search the fixed parameters in the first stage, we may find a solution giving only a local minimum.

If we have a program for obtaining $a_{i j k}$ in the whole model space, this enables us to use any of the above parametric models by setting $I, J$, and $K$ to appropriate values.

\section{Data}

It is obvious that improvements in the quantity and quality of the data allow Vol. 43, No. 3, 1995 
advances in the inversion analyses to be made. Recently high-quality digital seismograph networks have been established; data from these networks have led to great progress in our understanding of the rupture processes actually occurring in the source region. In the near future, as the receiver coverage becomes sufficiently dense, we will be able to obtain more reliable solutions with finer resolution.

Many investigators have attempted to combine different kinds of data. The use of different kinds of data provides two advances. One is that the amount of data available is increased and the azimuthal coverage is also improved. Another is that different kinds of data constrain different model parameters well.

To retrieve the temporal and spatial history of the rupture process of a large earthquake, either or both of the far-field $\mathrm{P}$-waveforms and the strong motion data have often been used, and sometimes the far-field SH wave data have been added. In the far-field waveform inversion, we usually use direct body waves at epicentral distances of $30^{\circ}$ to $90^{\circ}$, where there are no complications in the $\mathrm{P}$ and $\mathrm{S}$ waves due to Earth structure. Seismograms at ranges less than $30^{\circ}$ are avoided due to multiple arrivals caused by the upper mantle triplications, and seismograms at ranges greater than $90^{\circ}$ are avoided due to core shadow zones. This limitation for epicentral distances often leads to poor station coverage, when there are no stations in some azimuthal sector. To use observations at a large number of well distributed stations, Ruff and Kanamori (1983) and Lynnes and Ruff (1985), respectively, attempted to incorporate long-period diffracted P-waves and long-period PP waves. When using PP phases, we must take into account a $-\pi / 2$ phase shift, as was pointed out by Jeffreys and Lapwood (1957) and experimentally verified by Shimamura and Sato (1965). Satake (1985) and lida et al. (1990) have examined effects of station coverage on the accuracy of the inversion solution.

It may be difficult to observe temporal variations of the rupture process with a period less than several seconds using far-field data. In order to estimate the short period temporal variation of the rupture process, it is necessary to analyze strong motion seismograms recorded near the source region. Such strong motion records also enable us to investigate moderate-size earthquakes.

Use of both body waves and surface waves is very useful for moment tensor inversion. One reason is that, as mentioned above, we can obtain good receiver coverage because surface waves are available at epicentral ranges greater than $90^{\circ}$, and sometimes we have a station where the surface waves are off-scale but the body waves are on-scale. Another reason, which may be more essential, is as follows. Kanamori and Given (1981) pointed out that $M_{y z}$ and $M_{x z}$ (the $z$-axis is taken as the vertical direction) of a shallow earthquake cannot be well determined only from surface waves because the excitation functions for surface waves due to these elements have very small amplitude. On the other hand, body waves can constrain these two elements as well as the other elements (Honda and Seno, 1989; Kawakatsu, 1990) though the resolution of the nodal strike may not be so good as the surface waves.

Yoshida and Koketsu (1990) simultaneously inverted geodetic data and strong motion seismograms to obtain the rupture process of the 1984 Naganoken-Seibu earthquake. They demonstrated that combining geodetic data and waveform data 
improved the resolution of slip distribution, in particular, on the shallow part of the fault plane.

Tsunami waveform data are also useful to investigate fault heterogeneities of large submarine earthquakes (e.g., Satake, 1988). As another paper in this special issue reviews tsunami seismology, we omit the details in this paper.

\section{Green's Function}

It is important to use accurate Green's functions in order to obtain suitable solutions. Both synthetic and empirical Green's functions have been used. When inverting far-field body wave data, synthetic Green's functions are usually computed using flat-layered velocity structures. However, many earthquakes for which investigators have applied inversion are large shallow earthquakes in subduction zones, and laterally homogeneous near-source structure may not be sufficient for such earthquakes. Wiens (1987) and Okamoto and Miyatake (1989) found that reverberations in the water layer near the source significantly affect the far-field body waveforms and that this effect is extremely sensitive to seafloor topography. They pointed out that observed high amplitude water multiples may be misidentified as multiple sources if we use the Green's functions for a horizontal seafloor. Yoshida (1992) computed the Green's function using a non-flat seafloor model on the basis of ray theory and inverted waveform data from two large shallow earthquakes.

Waveform data with shorter wavelengths are more sensitive to heterogeneity of the structures. The assumption of a laterally homogeneous velocity structure is usually not good for modeling local strong ground motion records. Recently, methods for computing synthetic waveforms for two- or three-dimensional structures have been making rapid advances (e.g., Koketsu et al., 1991); however, at the present we are not yet at a stage where these method can be applied to practical inversion analyses. Even if the computation technique is practical, we often meet cases where we lack knowledge about the detailed structure of the regions near the source or beneath the stations. It is important to investigate velocity structures for computing accurate synthetic waveforms as well as for many other geophysical purposes.

When we lack information on effects of complex structures, empirical Green's functions may be useful because they automatically include the effects of a typically complex propagation path. Iida and Hakuno (1984), Fukuyama and Irikura (1986, 1989), Fukuyama (1991) and Ishihara et al. (1992) used foreshock and/or aftershock records as empirical Green's functions to analyze the rupture process of the main shock. Because the Green's functions are sensitive to both source mechanisms and depths, ideally we need records from aftershocks with the same mechanism as the main shock and with a good depth coverage. If we want to retrieve variation in the rake of the main shock, it would be desirable to use records from a pair of aftershocks with the same fault plane geometry but different rakes to express the mainshock records as a linear combination of them. However, an ideal set of such Green's functions is rarely available. Careful correction has to be done to use actual aftershock records as a relatively high-order approximation of the Green's functions. Fukuyama and Irikura (1986), who studied the spatial variation in slip magnitude of the 1983 Japan Sea

Vol. 43, No. 3, 1995 
earthquake, used an aftershock occurring south of the main shock fault as the empirical Green's functions for the southern part of the fault and an aftershock occurring north of the main shock fault for the northern part. They made a correction for the radiation pattern taking into account the difference in the mechanism. The amplitude correction was done using the radiation pattern of direct $S$ waves because they considered the solution would be mainly affected by the $S$ phase; note, however, that this correction was not valid for the other phases such as multiply reflected waves.

Despite many difficulties, empirical Green's functions hold potential for estimating source functions from complex records of strong ground motion and broadband body waves.

\section{Constraints}

In this section, constraints used in the inversion analysis are discussed. For simplicity, we deal with the case of linear inversion for determination of spatial slip distribution taking only $a_{k}$ as unknown, but the following constraints can be used in any type of inversion. We may write the observational equation in vector notation as

$$
A a \cong d,
$$

where $A$ is the matrix of synthetics, $d$ is the data vector formed by stringing together the observed waveforms for all the stations, and $\boldsymbol{a}$ is the model vector of which the $k$ th element is $a_{k}$. The $k$ th column of $\boldsymbol{A}$ is composed of the synthetic waveforms $f(t)$ from the $k$ th subfault with unit moment for all the stations. The classical least squares solution minimizes the squared residual $S_{d}$ given by

$$
S_{d}=|\boldsymbol{d}-\boldsymbol{A a}|^{2}
$$

where | | represents the Euclidean norm.

To obtain a clear image of the source, we must divide the fault into a large number of subfaults. However, an increase of the number of model parameters may give rise to an instability in the solution. A small change in the data will result in a large change in the solution, and hence more than one solution can fit the data almost equally well. But these will not always be physically reasonable solutions. Instability can arise when we obtain very small eigenvalues by applying the singular value decomposition to the matrix $A$, as $A$ will then be a highly ill-conditioned matrix with a large value of the condition number. The unstable part of the solution is given by a linear combination of the eigenvectors of small eigenvalues, for which variance is very large because the variance is inversely proportional to the squared eigenvalue. To suppress the instability and to obtain a physically reasonable solution we need additional constraints.

If we have a priori information on values of the model parameters, we can use this prior information as the additional constraint. The prior information may be written in the same form as the observational equation:

$$
a \cong a^{0} \text {, }
$$

where $a^{0}$ is a prior estimate for the model vector. Instead of minimizing the data misfit $S_{d}$, we find the solution that minimizes $S$ given by 


$$
S=S_{d}+\beta^{2}\left|a^{0}-a\right|^{2},
$$

where $\beta^{2}$ may be regarded as a tradeoff parameter to adjust the relative weight of the constraint versus the misfit reduction. If the variance of errors in the data is known and given by $\sigma d^{2}$, and that of the prior estimate is $\sigma p^{2}, \beta^{2}$ should be given by $\beta^{2}=\sigma d^{2} / \sigma p^{2}$. To stabilize the problem, this constraint has been used by many authors (e.g., Nabelek, 1985; Fukuyama and Irikura, 1986, 1989). Some of them set $\boldsymbol{a}^{0}=\mathbf{0}$, which leads to a minimum length solution, i.e., giving the minimum seismic moment in the present case. If we have prior data on some quantity which is linearly related to the model parameters, this information can be incorporated in the scheme in the same way. We write the constraint as

$$
B a \cong c
$$

and then minimize

$$
S=S_{d}+\beta^{2}|\boldsymbol{c}-\boldsymbol{B a}|^{2} .
$$

When we want to constrain the seismic moment to a given value, we use this formulation setting $\boldsymbol{B}=(1,1, \cdots, 1)$.

Another type of constraint which is often used (e.g., Hartzell and Heaton, 1983; Yoshida, 1988) is a positivity constraint:

$$
a>0,
$$

which means to prohibit negative slip. There are several techniques for incorporating such an inequality constraint into the least squares procedure, for example, the non-negative least squares method developed by Lawson and Hanson (1974) and the penalty function method. Koketsu (1989) compared their efficiency. The constraint Eq. (24) is easily extended to

$$
B a>0 \text {, }
$$

which is useful when some physical quantities are required to be positive. For example, in the case of moment tensor inversion, the constraint from the P-wave first motion data is written in the form of Eq. (25) by representing the radiation pattern as $\boldsymbol{B a}$.

We often encounter the problem of how to choose the subfault size, or the number of subfaults. If we take the number of subfaults to be as many as possible to extract detailed information of slip from the data, the classical least squares inversion is unlikely to constrain such a highly parametrized model. On the other hand, if only a few subfaults are used, there is not sufficient spatial resolution of fault details. One way to solve the difficulty is to apply smoothing constraints using a flexible model with a large number of relatively small subfaults (e.g., Hartzell and Heaton, 1983; Beroza and Spudich, 1988; Yoshida, 1989). Different measures of the roughness have been proposed, most of which are based on the first or second derivative of the model with respect to the spacial coordinates. When the grid points are distributed on a two-dimensional fault plane, a smoothing constraint may be presented as

$$
\nabla^{2} a_{k} \cong 0 \quad k=1,2, \cdots, K,
$$

Vol. 43, No. 3, 1995 
where $\nabla^{2}$ is the two-dimensional, finite difference Laplacian operator defined by

$$
\nabla^{2} a_{k}=4 a_{k}-a_{k+1}-a_{k-1}-a_{k+M}-a_{k-M},
$$

where $M$ is the number of grids along the fault length. We will minimize

$$
S=S_{d}+\beta^{2} \sum_{k}\left(\nabla^{2} a_{k}\right)^{2} .
$$

This is equivalent to Eq. (23) with $\boldsymbol{B}$ set to be the Laplacian operator matrix and $\boldsymbol{c}$ to be 0 . If we take a suitable value of $\beta^{2}$, we can find the smoothest, or simplest solution without disgrading the fit to the data. Choosing the simplest solution reduces the temptation to overinterpret the data. Such smoothing constraints have been also used in tomographic inversion for velocity structure (e.g., Lees and Crosson, 1989).

Another way to choose the proper number of subfaults is to use Akaike's information criterion (AIC). Takeo (1992) ran many inversions changing the subfault size and chose the size that minimized AIC as the preferable size.

When using any of the above constraints, the resultant solution depends on the value of the tradeoff parameter $\beta^{2}$. If we take too large a value for $\beta^{2}$, the solution cannot fit the data well. On the other hand, if we choose too small a $\beta^{2}$, the solution becomes unstable due to noise in the data. To determine the proper value of $\beta^{2}$ objectively, Akaike's Bayesian information criterion (ABIC) is useful (Yoshida, 1989; Yabuki and Matsu'ura, 1992).

Usually more than one constraint is simultaneously used. Hartzell (1989) studied the effects of the choice of the stabilizing constraint on the solution. He also compared the use of different data sets, different parametrizations of the source, and synthetic versus empirical Green's functions.

\section{Concluding Remarks}

Through the waveform inversion, complex rupture patterns have so far been obtained for individual earthquake sources. As space is too limited to summarize these studies, we briefly touch upon some of the works compiling characteristic features of the earthquake source. Kikuchi and Fukao (1987) studied several great earthquakes along subduction zones and pointed out that constancy of the local stress drop as well as the average stress drop holds among various magnitudes of earthquakes, which suggested an essential similarity in the heterogeneous distribution of slip. They also attempted to interpret the nature of the subevent sequence in terms of an asperity model. Fukao and Kikuchi (1987) discussed stress drop and rupture duration of subevents for eighteen deep and intermediate-depth earthquakes. Takeo and Mikami (1990) compiled detailed rupture processes of six intraplate earthquakes in Japan, and compared with each other to make clear common features of an earthquake rupture process. They also compared the spatial slip variation of the main shock with distributions of precisely determined aftershocks and found that aftershocks tend to occur near the edge of the large slip region and in the small slip region. Similar results have been reported by many authors (e.g., Mendoza and Hartzell, 1988). Kikuchi (1991) gave a thorough review of advances for the last decade in understanding the earthquake source behaviour.

There are some inversion works relating to volcanos. For example, Takeo (1988) 
compared the slip distribution of the 1980 Izu-Hanto-Toho-Oki earthquake with the distribution of the submarine monogenetic volcanoes and found the fault beneath the volcanoes was characterized by small slip and deceleration of rupture propagation because of the mechanical weakness of volcanos. Oura et al. (1992) analyzed the waveforms from the 1989 Ito-Oki earthquake and found that a pressure drop occurred just under the Teishi Knoll volcano which erupted four day after the earthquake. They suggested that a pressure drop led to magma ascent towards a surface eruption. Takeo et al. (1990) and Fukuyama and Takeo (1990) proposed kinematic seismic source models associated with the eruptions of Izu-Oshima volcano of 1987 using a waveform inversion technique

As we have discussed, the recent development of inversion methods enabled us to retrieve the kinematic behaviour of the earthquake source in detail. However, these inversions are in some ways unsatisfying because the solutions. for the temporal and spatial distribution of the slip tell us very little about the stress and the strength on the fault or the constitutive law of the fault zone material. Areas with high moment release on the fault are often interpreted as an asperity. But if an asperity is defined as a patch with high strength, it is desirable to obtain direct evidence of high strength from the data without speculation. Recently using the inversion results as data, Quin (1990), Miyatake (1992), and Spudich (1992) attempted to infer the yield strength and stress drop distribution by numerically simulating spontaneous rupture propagation. We may anticipate that in the future inversion methods will be developed to directly extract information about distribution of yield strength, stress drop or critical displacement in the source region from the waveform data.

I thank Dr. Peter Sammonds and Prof. Robert J. Geller for reading the manuscript and improving my English. I also express thanks to an anonymous reviewer for his valuable suggestion.

\section{REFERENCES}

Aki, K. and P.G. Richard, Quantitative Seismology: Theory and Methods, W. H. Freeman and Company, San Francisco, 932 pp., 1980.

Beroza, G. C. and P. Spudich, Linearized inversion for fault rupture behavior: application to the 1984, Morgan Hill, California earthquake, J. Geophys. Res., 93, 6275-6296, 1988.

Burdick, L. J. and G. R. Mellman, Inversion of the body waves from the Borrego Mountain earthquake to the source mechanism, Bull. Seismol. Soc. Am., 66, 1485-1499, 1976.

Das, S. and B. V. Kostrov, Inversion for seismic slip rate history and distribution with stabilizing constraints: application to the 1986 Andreanof Islands earthquake, J. Geophys. Res., 95, 6899-6913, 1990.

Dziewonski, A. M. and F. Gilbert, Temporal variation of the seismic moment tensor and the evidence of precursive compression for two deep earthquakes, Nature, 247, 185-188, 1974.

Dziewonski, A. M. and J. H. Woodhouse, An experiment in systematic study of global seismicity: centroid moment tensor solutions for 201 moderate and large earthquakes in 1981, J. Geophys., Res., 88, 3247-3271, 1983.

Dziewonski, A. M., T. A. Chou, and J. H. Woodhouse, Determination of earthquake source 
parameters from waveform data for studies of global and regional seismicity, J. Geophys. Res., 86, 2825-2852, 1981.

Ekstrom, G., A very broad band inversion method for the recovery of earthquake source parameters, Tectonophysics, 166, 73-100, 1989.

Fukao, Y. and M. Kikuchi, Source retrieval for mantle earthquakes by iterative deconvolution of long-period P-waves, Tectonophysics, 144, 249-269, 1987.

Fukushima, T., D. Suetsugu, I. Nakanishi, and I. Yamada, Moment tensor inversion for near earthquakes using long-period digital seismograms, J. Phys. Earth, 37, 1-29, 1989.

Fukuyama, E., Inversion for the rupture details of the 1987 east Chiba earthquake, Japan, using a fault model based on the distribution of relocate aftershocks, J. Geophys. Res., 96, 8205-8217, 1991.

Fukuyama, E. and K. Irikura, Rupture process of the 1983 Japan Sea (Akita-Oki) earthquake using a waveform inversion method, Bull. Seismol. Soc. Am., 76, 1623-1640, 1986.

Fukuyama, E. and K. Irikura, Heterogeneity of the 1980 Izu-Hanto-Toho-Oki earthquake rupture process, Geophys. J. Int., 99, 711-722, 1989.

Fukuyama, E. and M. Takeo, Analysis of the near-field seismogram observed during the eruption of Izu-Oshima volcano on November 16, 1987, Bull. Volcanol. Soc. Jpn., 35, 283-297, 1990.

Hartzell, S., Comparison of seismic waveform inversion results for the rupture history of a finite fault: application to the 1986 North Palm Springs, California, earthquake, J. Geophys. Res., 94, 7515-7534, 1989.

Hartzell, S. H. and T. H. Heaton, Inversion of strong ground motion and teleseismic waveform data for the fault rupture history of the 1979 Imperial Valley, California, earthquake, Bull. Seismol. Soc. Am., 73, 1553-1585, 1983.

Hatanaka, Y. and M. Takeo, Detail rupture process of the 1975 central Oita, Japan, earthquake inferred from near-field data, J. Phys. Earth, 37, 251-264, 1989.

Hirata, K. and I. Kawasaki, Space-time dependent moment tensor, Prog. Abstr. Seismol. Soc. Jpn., 2, 16, 1988.

Honda, S. and T. Seno, Seismic moment tensors and source depths determined by the simultaneous inversion of body and surface waves, Phys. Earth Planet. Inter., 57, 311-329, 1989.

Iida, M. and M. Hakuno, The difference in the complexities between the 1978 Miyagiken-Oki earthquake and the 1968 Tokachi-Oki earthquake from a viewpoint of short-period range, Nat. Disas. Sci., 6, 1-26, 1984.

Iida, M., T. Miyatake, and K. Shimazaki, Preliminary analysis of resolving power of existing strong-motion arrays for source inversion, J. Phys. Earth, 38, 285-304, 1990.

Ishihara, Y., Y. Fukao, I. Yamada, and H. Aoki, Rising slope of moment rate functions: the 1989 earthquakes off east coast of Honshu, Geophys. Res. Lett., 19, 873-876, 1992.

Jeffreys, H. and E. R. Lapwood, The reflection of a pulse within a sphere, Proc. R. Soc., Ser. $A, 241,455-479,1957$.

Kanamori, H. and J. W. Given, Use of long-period surface waves for rapid determination of earthquake source parameters, Phys. Earth Planet. Inter., 27, 8-31, 1981.

Kanamori, H. and G. S. Stewart, Seismological aspects of the Guatemala earthquake of February 4, 1976, J. Geophys. Res., 83, 3427-3434, 1978.

Kawakatsu, H., CMT solution of the Izu-Oshima-Kinkai earthquake of January 14, 1978, Zisin, Ser. 2, 43, 447-450, 1990 (in Japanese).

Kawakatsu, H., Insignificant isotropic component in the moment tensor of deep earthquakes, Nature, 351, 50-53, 1991. 
Kikuchi, M., Complexity of earthquake source processes, Zisin, Ser. 2, 44, 301-314, 1991 (in Japanese).

Kikuchi, M. and Y. Fukao, Iterative deconvolution of complex body waves from great earthquakes-the Tokachi-Oki earthquake of 1968, Phys. Earth Planet. Inter., 37, 235-248, 1985.

Kikuchi, M. and Y. Fukao, Inversion of long-period P-waves from great earthquakes along subduction zones, Tectonophysics, 144, 231-247, 1987.

Kikuchi, M. and H. Kanamori, Inversion of complex body waves, Bull. Seismol. Soc. Am., 72, 491-506, 1982.

Kikuchi, M. and H. Kanamori, Inversion of complex body waves-III, Bull. Seismol. Soc. Am., 81, 2335-2350, 1991.

Kikuchi, M. and K. Sudo, Inversion of teleseismic P waves of Izu-Oshima, Japan earthquake of January 14, 1978, J. Phys. Earth, 32, 161-171, 1984.

Koketsu, K., Hypocenter determination with non-negative depth, Zisin, Ser. 2, 42, 325-331, 1989 (in Japanese).

Koketsu, K., B. L. N. Kennett, and H. Takenaka, 2-D reflectivity method and synthetic seismograms for irregularly layered structures-II. Invariant embedding approach, Geophys. J. Int., 105, 119-130, 1991.

Koyama, J., Time-dependent moment tensor inversion for the 1983 Japan Sea earthquake, Zisin, Ser. 2, 40, 405-416, 1987 (in Japanese).

Kuge, K. and H. Kawakatsu, Analysis of a deep "non double couple" earthquake using very broadband data, Geophys. Res. Lett., 17, 227-230, 1990.

Langston, C. A., Source inversion of seismic waveforms: the Koyna, India, earthquakes of 13 September 1967, Bull. Seismol. Soc. Am., 71, 1-24, 1981.

Lawson, C. L. and R. J. Hanson, Solving Least Squares Problems, Prentice-Hell, Englewood Cliffs, 340 pp., 1974.

Lees, J. M. and R. S. Crosson, Tomographic inversion for three-dimensional velocity structure at Mount St. Helens using earthquake data, J. Geophys. Res., 94, 5716-5728, 1989.

Lynnes, C. S. and L. J. Ruff, Use of the PP phase to study the earthquake source, Geophys. Res. Lett., 12, 514-517, 1985.

Matsu'ura, M., Development of inversion theory in geophysics, Zisin, Ser. 2, 44, 53-62, 1991 (in Japanese).

Mendiguren, J. A. and K. Aki, Source mechanism of the deep Colombian earthquake of 1970 July 31 from the free oscilation data, Geophys. J. R. Astron. Soc., 55, 539-556, 1978.

Mendoza, C. and S. H. Hartzell, Aftershock patterns and main shock faulting, Bull. Seismol. Soc. Am., 78, 1438-1449, 1988.

Miyashita, K. and M. Matsu'ura, Inversion analysis of static displacement data associated with the Alaska earthquake of 1964, J. Phys. Earth, 26, 333-349, 1978.

Miyatake, M., Reconstruction of dynamic rupture process of an earthquake with constraints of kinematic parameters, Geophys. Res. Lett., 19, 349-352, 1992.

Mori, J. and K. Shimazaki, Inversion of intermediate-period Rayleigh waves for source characteristics of the 1968 Tokachi-Oki earthquake, J. Geophys. Res., 90, 11374-11382, 1985.

Nabelek, J., Geometry and mechanism of faulting of the $1980 \mathrm{El}$ Asnam, Algeria, earthquake from inversion of teleseismic body waves and comparison with field observations, J. Geophys. Res., 90, 12713-12728, 1985.

Nakanishi, I. and H. Kanamori, Source mechanisms of twenty-six large, shallow earthquakes 
$\left(M_{\mathrm{S}} \geq 6.5\right)$ during 1980 from P-wave first motion and long-period Rayleigh wave data, Bull. Seismol. Soc. Am., 74, 805-818, 1984.

Nakanishi, I., Y. Hanakago, T. Moriya, and M. Kasahara, Performance test on long-period moment tensor determination for near earthquakes by a sparse local network, Geophys. Res. Lett., 18, 223-226, 1991.

Okamoto, T. and T. Miyatake, Effects of near source seafloor topography on long-period teleseismic P waveforms, Geophys. Res. Lett., 16, 1309-1312, 1989.

Olson, A. H. and R. J. Apsel, Finite faults and inverse theory with applications to the 1979 Imperial Valley earthquake, Bull. Seismol. Soc. Am., 72, 1969-2001, 1982.

Oura, A., S. Yoshida, and K. Kudo, Rupture process of the Ito-Oki, Japan, earthquake of July 9, 1989 and interpretation as a trigger of volcanic eruption, Geophys. J. Int., 109, 241-248, 1992.

Quin, H., Dynamic stress drop and rupture dynamics of the October 15, 1979 Imperial Valley, California, earthquake, Tectonophysics, 175, 93-117, 1990.

Ruff, L. and H. Kanamori, The rupture process and asperity distribution of three great earthquakes from long-period diffracted P-waves, Phys. Earth Planet. Inter., 31, 202-230, 1983.

Ruff, L. J. and B. W. Tichelaar, Moment tensor rate functions for the 1989 Loma Prieta earthquake, Geophys. Res. Lett., 17, 1187-1190, 1990.

Satake, K., Effects of station coverage on moment tensor inversion, Bull. Seismol. Soc. Am., 75, 1657-1667, 1985.

Satake, T., Inversion of tsunami waveforms for the estimation of a fault heterogeneity of large submarine earthquakes: 1968 Tokachi-oki and 1983 Japan Sea earthquakes, J. Geophys. Res., 94, 5627-5636, 1988.

Sato, T., Rupture characteristics of the 1983 Nihonkai-Chubu (Japan Sea) earthquake as inferred from strong motion accelerograms, J. Phys. Earth, 33, 525-557, 1985.

Seno, T. and S. Honda, Depth extent analysis of the 1981 October 16 Chile earthquake, Bull. Earthq. Res. Inst., Univ. Tokyo, 65, 1-32, 1990.

Shimamura, H. and R. Sato, Model experiments on body waves-travel times, amplitudes, wave forms and attenuation, J. Phys. Earth, 13, 10-33, 1965.

Sipkin, S. A., Interpretation of non-double-couple earthquake mechanisms derived from moment tensor inversion, J. Geophys. Res., 91, 531-547, 1986.

Spudich, P. K. P., On the inference of absolute stress levels from seismic radiation, Tectonophysics, 211, 99-106, 1992.

Strelitz, R. A., The fate of the downgoing slab: a study of the moment tensor from body waves of complex deep-focus earthquakes, Phys. Earth Planet. Inter., 21, 83-96, 1980.

Suetugu, D. and I. Nakanishi, Re-examination of fault model for the 1982 Urakawa-oki earthquake by analyses of seismic, geodetic, and tsunami data, J. Phys. Earth, 36, 53-67, 1988.

Sugi, N., M. Kikuchi, and Y. Fukao, Mode of stress release within a subducting slab of lithosphere: implication of source mechanism of deep and intermediate-depth earthquakes, Phys. Earth Planet. Inter., 55, 106-125, 1989.

Takenaka, H., Strong-motion modeling of the 1980 Izu-Hanto-Toho-Oki earthquake be inversion method, J. Fac. Sci., Hokkaido Univ., Ser. VII (Geophys.), 8, 155-172, 1987.

Takeo, M., Rupture process of the 1980 Izu-Hanto-Toho-Oki earthquake deduced from strong motion seismograms, Bull. Seismol. Soc. Am., 78, 1074-1091, 1988.

Takeo, M., Rupture process of the 1974 Izu-Hanto-Oki earthquake, Zisin, Ser. 2, 42, 59-66, 1989 (in Japanese). 
Takeo, M., Detailed rupture processes of offshore Ito earthquakes on July 9, 1989, preceding a submarine volcanic eruption, J. Geophys. Res., 97, 6613-6627, 1992.

Takeo, M. and N. Mikami, Inversion of strong motion seismograms for the source process of the Naganoken-Seibu earthquake of 1984, Tectonophysics, 144, 271-285, 1987.

Takeo, M. and N. Mikami, Fault heterogeneity of inland earthquakes in Japan, Bull. Earthq. Res. Inst., Univ. Tokyo, 65, 541-569, 1990.

Takeo, M., H. Yamasato, I. Furuya, and M. Seino, Analysis of long-period seismic waves excited by the November 1987 eruption of Izu-Oshima volcano, J. Geophys. Res., 95, 19337-19393, 1990.

Tanimoto, T. and H. Kanamori, Linear programming approach to moment tensor inversion of earthquake sources and some tests on the three-dimensional structure of the upper mantle, Geophys. J. R. Astron. Soc., 84, 413-430, 1986.

Tarantola, A., Inverse Problem Theory: Methods for Data Fitting and Model Parameter Estimation, Elsevier, Amsterdam, 1987.

Trifunac, M. D., A three-dimensional dislocation model for the San Fernando, California, earthquake of February 9, 1971, Bull. Seismol. Soc. Am., 64, 149-172, 1974.

Umeda, Y., High-amplitude seismic waves radiated from the bright spot of an earthquake, Tectonophysics, 175, 81-92, 1990.

Ward, S. N. and S. E. Barrientos, An inversion for slip distribution and fault shape from geodetic observations of the 1983, Borah Peak, Idaho, earthquake, J. Geophys. Res., 91, 4909-4919, 1986.

Wiens, D. A., Effects of near source bathymetry on teleseismic P waveforms, Geophys. Res. Lett., 14, 761-764, 1987.

Yabuki, T. and M. Matsu'ura, Geodetic data inversion using a Bayesian information criterion for spatial distribution of fault slip, Geophys. J. Int., 109, 363-375, 1992.

Yoshida, S., Waveform inversion for rupture processes of two deep earthquakes in the Izu-Bonin region, Phys. Earth Planet. Inter., 52, 85-101, 1988.

Yoshida, S., Waveform inversion using ABIC for the rupture process of the 1983 Hindu Kush earthquake, Phys. Earth Planet. Inter., 56, 389-405, 1989.

Yoshida, S., Waveform inversion for rupture process using a non-flat seafloor model: application to 1986 Andreanof Islands and 1985 Chile earthquakes, Tectonophysics, 211, 45-59, 1992.

Yoshida, Y. and K. Abe, Source mechanism of the Luzon, Philippines earthquake of July 16, 1990, Geophys. Res. Lett., 19, 545-548, 1992.

Yoshida, S. and K. Koketsu, Simultaneous inversion of waveform and geodetic data for the rupture process of the 1984 Naganoken-Seibu, Japan, earthquake, Geophys. J. Int., 103, 355-362, 1990.

Vol. 43, No. 3, 1995 